\title{
A comprehensive study on the relationship between meaning and spirituality at work with job happiness, positive affect and job satisfaction
}

\author{
Mohsen Golparvar ${ }^{\mathrm{a}^{*}}$ and Hassan Abedini
}

${ }^{a}$ Associate Professor, Psychology PhD, Faculty of Psychology and Education, Islamic Azad University, Esfahan Branch (Khorasgan), Esfahan, Iran ${ }^{b}$ MA in I/O Psychology, Faculty of Psychology and Education, Islamic Azad University, Esfahan Branch (Khorasgan), Esfahan, Iran

\section{H R O N I C L E A B S T R A C T}

\section{Article history:}

Received June 28, 2013

Received in revised format

19 October 2013

Accepted 20 December 2013

Available online

December 272013

Keywords:

Meaning at work

Spirituality at work

Job happiness

Positive affect

Job satisfaction

\begin{abstract}
Positive affectivity and affective management are among important issues for the most desirable effectiveness of employees in the workplace. Accordingly, in this research, the role of meaning and spirituality at workplace is considered for job happiness, positive affect and job satisfaction. To this end, within a correlation study, with the selection of two hundred and four employees of two custom organizations in Esfahan and Tehran, in Iran, who answer meaning and spirituality at work, job happiness, positive affect and job satisfaction questionnaires, the research hypotheses have been tested through Pearson's correlation and structural equation modeling. The results showed that there were significant relationships between meaning and spirituality at work, job happiness, positive affect and job satisfaction. Results of structure equation modeling revealed that during two chain models, at first meaning and spirituality at work are linked to job happiness and positive effect. Then job happiness and positive effect cause reinforcement of job satisfaction. The results of this study showed that meaning and spirituality at work cause positive affective spillover from job happiness and positive affect to job satisfaction.
\end{abstract}

\section{Introduction}

One of the primary concerns in most organizations is to find out the process on having happy, joyful and satisfied employees in the workplace. This concern arises from the fact that employees with joy and happiness in various forms are staffs with better performance and effectiveness who could assist organizations in reaching their goals in the best possible way (Hartel \& Page, 2009; Eby et al., 2010; Nelson \& Knight, 2010). Efforts and the outcome of decades of researches and studies have identified several factors that each one could reinforce happiness, satisfaction and job-related positive affect on the people in the workplace through certain way. Research evidences suggest that factors such as organizational and situational organizational health, organizational climate and culture, leadership 
and management systems and personal factors including perception, cognition, and personal characteristics are the primary determinants of affective and emotional experiences of people in workplace (Brief \& Weiss, 2002; Grandey et al., 2002; Judge \& Klinger, 2008; Duckworth et al., 2009). It is quite natural that every researcher and scholar in the field of human behavior in the workplace has shown interest to one of the two categories: individual and organizational factors, and in some cases, interaction of these two cases. In this study, in terms of the individual perspective, we study the role of meaning and spirituality at work for job happiness, job related positive affect and job satisfaction.

\section{Literature Review}

\subsection{Meaning at Work}

One of the interested research topics for many researchers is to determine the meaning in life. There has always been a question that in the sense of having meaning and purpose in life and the implications for human? Many scholars describe the meaning in life as a form of natural need to understand the importance of living and believe that meaning gives importance in life (Brooke \& Parker, 2009; Steger \& Dik, 2009). Therefore, the need for meaning could be among the most basic human needs, in which humans seek the way to give meaning to their lives and to make it understandable (Rosso et al., 2010; Steger et al., 2012). The same holds about the meaning at work, which is part of the meaning in life (Brooke \& Parker, 2009).

From the viewpoint of providing consequences for human health, it could take into consideration that meaning at work consists of systematic goal orientation and motivation to move towards the goals based on a sense of control over events and self-assessment. An overview to theories of meaning in life and at work shows that this phenomenon through a sense of purpose and control could lead to positive outcomes for humans. Several researches have shown that meaning at work alongside or in the context of spirituality at work could be lead to reinforcing job happiness and job-related positive effects and following it to reinforcing job satisfaction (Brooke \& Parker, 2009; Steger \& Dik, 2009; Steger et al., 2012).

\subsection{Spirituality at Work}

Scholars and researchers have taken spirituality at work as personal experience into consideration from various viewpoints and perspectives (Young, 2012). In an overview, we can say that spirituality at work has the deep philosophical-individual themes of a sense of wholeness and connectedness at work and deep understanding of the work values. From such a perspective, spirituality can be expressed as inspiring and motivating force for constant search and finding meaning and purpose in working life, along with a deep understanding of the value of work, life, the immensity of the universe, the natural beings and personal belief systems (Hasnain et al., 2011). Several theoretical formulations about levels of spirituality at work have been provided that one of the most important is spirituality at individual and group level.

Kinjerski and Skrypnek (2006) believed that spirituality at work at the individual level includes six physical, affective, cognitive, interpersonal, spiritual and mystical dimensions. Each of these dimensions with one of the aspects of human existence including biological, psychological, social and spiritual is related intimately. Among these six dimensions, affective dimension of spirituality at work including experiencing the feelings of excitement and happiness at work could result to a deeper feeling of joy and peace (Kinjerski \& Skrypnek, 2006). 
Real feeling of people at work of rapturous, along with feeling of satisfaction from being a part of such an important and meaningful processes and phenomenon, they will lead them to experience feelings of happiness, joy and satisfaction. In other words, personal affective spirituality brings effectiveness of positive state associated with affective well-being for individuals and so the final and mediating result of it will be personal satisfaction from their job and work. Research evidence supports the idea that spirituality at work with close linkage with meaning at work cause experience in feelings of job happiness and positive affect and ultimately job satisfaction, too (Clark et al., 2007; Giacalone \& Jurkiewicz, 2010; Adawiyah, Shariff, Saud \& Mokhtar, 2011).

\subsection{The Role of Meaning and Spirituality in Job Happiness}

Happiness could be considered as experiencing of positive affect, not experiencing negative affect and general feeling of satisfaction in life (Lyubomisky \& Lepper, 1999; Warr \& Clapperton, 2009). Studies on happiness in the workplace show that in operational terms (functional form), this phenomenon may be as follows: Positive feelings associated with the action on the optimal use of available resources to overcome the challenges encountered during work (Pryce-Jones, 2010). From such a viewpoint, happiness is a source of affective capital, which brings appropriate action in every moment of work and job experience for people (Boehm \& Lyubomirsky, 2008). Such an emphasis on the link between positive feelings and optimal action in job happiness is a view arising out of pragmatic approach to happiness that in this study, special emphasis has been on it (Downey, 2008; Pryce-Jones, 2010; Ashkanasy, 2011).

It still has not been agreed on what dimensions job happiness could have. However, the experiences of happiness oriented towards biological-psychio-social-spiritual approach can classified as nature of human existence and in terms of content, as one of the dimensions of psychological happiness (joy and enthusiasm in the human mental space to work), social happiness (joy and enthusiasm from job social ties and relations), spiritual happiness (joy and enthusiasm related to job purposeful and useful efforts) biological happiness (feeling of physical vitality at the time of performing job duties) (Golparvar, 2013a). However, each of these dimensions may practically not be segregated from other dimensions, but each dimension covers a dimension of human experience in dealing with job and job duties. Available research evidence shows that meaning and spirituality at work are among the potential factors for the reinforcement and promotion of job happiness level in different dimensions (Lyubomisky \& Lepper, 1999; Downey, 2008; Warr, 2009, 2013; Steger et al., 2012).

\subsection{The role of meaning and spirituality in job-related affect}

Studies conducted in the field of affects have discussed both positive and negative affective dimensions that were obtained from conducted factor analyses on self-evaluation tools, a multidimensional scale of aspects of affective features and mood expressions scales (De Nevea, \& Oswald, 2012). After discussing of two dimensions of positive and negative affect, the classification of two-dimensional affect by entering at the workplace, has been discussed as job-related positive affects (Barsade \& Gibson, 2007; Gloria, Faulk \& Steinhardt, 2013). Job-related positive affect, consist of affective such as feelings of joy, vitality, pride, comfort, pleasure, pride and enthusiasm that are associate with continuous physical activity, enough asleep, social relationships with close friends and strive for worthy goals (Hartel \& Page, 2009; Eby et al, 2010).

Positive affect also may be increased during regular physical activity, sleep pattern, having a friendly relationship and valuable goals (De Nevea, \& Oswald, 2012). Among the most important functions of positive affect is that it will increase intend to conflict and confrontation with the environment, including the social environment and helps people continue to live actively, vigorously, capability 
(Hartel \& Page, 2009). Job-related positive affect is also associated with higher levels of performance, effectiveness and more success (De Nevea, \& Oswald, 2012). People with job-related positive affect who seek connection with others will enjoy it and enjoy the trust and satisfaction in their social interaction. Among the most important functions of job-related positive affect is that it could nourish and reinforce levels of satisfaction with different aspects of job and job satisfaction as a one of other aspect of affective capital alongside job happiness (Karakas, 2010; Hasnain et al., 2011; Steger et al., 2012).

\subsection{The role of meaning and spirituality in job satisfaction}

Job satisfaction includes feelings and attitudes that a person has towards his/her various aspects of work and job (Wicker, 2011; Judge et al., 2008). Under the current approach, job satisfaction is an affective, behavioral and cognitive variable, (as a professional attitude) that has a relationship with a wide and considerable range of individual and organizational variables (Warr \& Inceoglu, 2012). Various factors in workplace could strengthen or weaken job satisfaction. Among debilitating factors of job satisfaction are job stress, poor (inadequate) management and supervision, injustice, performance appraisal system and imprecise promotion and burnout (Duggleby et al., 2009; Wicker, 2011). However, several variables can also become underlying of job satisfaction reinforcement.

Among the most important variables, which have the capacity of reinforcing of job satisfaction, we could point to organizational factors (including salary requirements, ability for development and promotion and organizational policies), environmental factors (such as conditions of supervision and management, conditions of work, human relations), nature of work and personal factors (such as personality traits, attitudes, perceptions, age, tenure) (Rode, 2004; Harrison et al., 2006; et al., 2006; Golden \& Veiga, 2008; Judge et al., 2008; Kaplan et al., 2009; Bowling et al., 2010; Volmer et al., 2011; Faulk et al., 2012; De Kok, 2013).

Based on some available research evidences, among the factors mentioned, meaning and spirituality are among the variables that could increase job satisfaction. The logic of the relationship between meaning and spirituality with job satisfaction is that meaning and spirituality could equip people to efficient ways to deal with stressful factors and to satisfy basic needs in people such as the need to affiliation and support (Brooke \& Parker, 2009; Karakas, 2010; Ho, 2011).

Several studies indicate that there was content distinction between job satisfaction with positive affect (Agho et al., 1992) and job happiness (Warr, 2009). The results of the previous studies show that there was a positive relationship between positive affect and job satisfaction (Judge \& Ilies, 2004; Fredrickson, 2009; Faulk et al., 2012), and between happiness and job satisfaction (Albano, 2009; Wang \& Yi, 2011; De Kok, 2013; Warr, 2013). On the other side, meaning and spirituality from affective dimension by providing joy, happiness and positive affect can enhance an individual's sense of job satisfaction (Ho, 2011; Steger et al, 2012).

\subsection{Research Conceptual Models}

Based on what has been said about the meaning and spirituality at work and its relationship to job happiness and job-related positive affect and then job satisfaction, in this study an approach known as spirituality based affective spillover has been proposed. Two models emerge from this approach for the study presented in Fig. 1. 


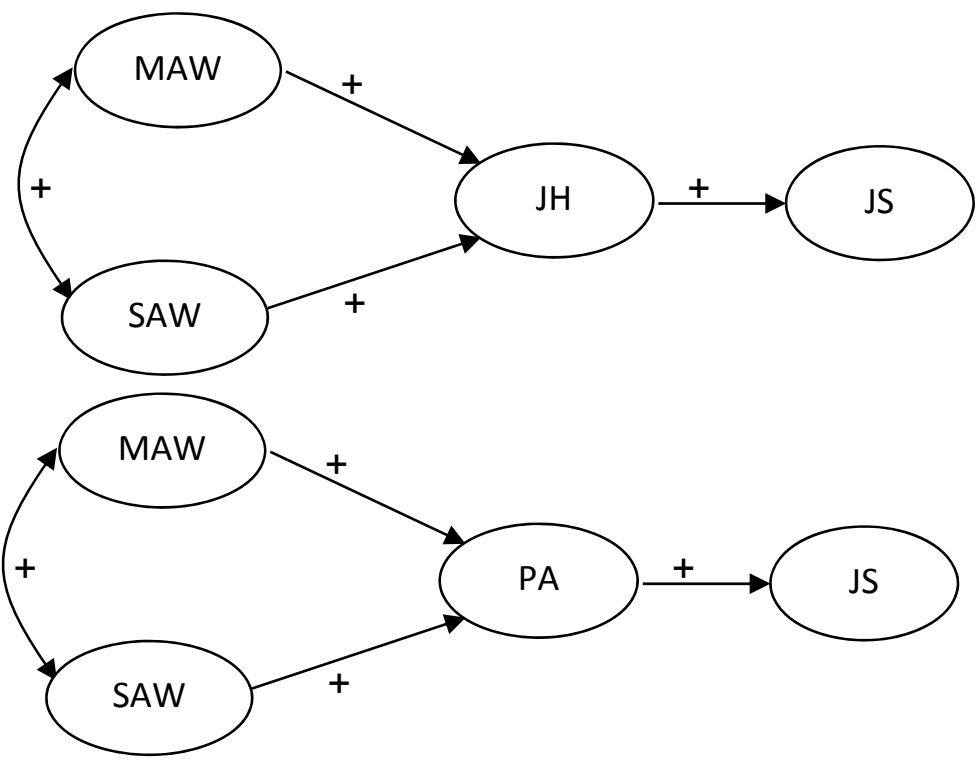

Fig. 1. The conceptual research models

Based on the approach of spirituality based affective spillover, the hypotheses of this study are as follows.

\section{The Research Hypotheses}

$\mathrm{H}_{1}$ : There is a significant positive correlation between meaning (MAW) and spirituality (SAW) at work and job happiness $(\mathrm{JH})$.

$\mathrm{H}_{2}$ : There is a significant positive correlation between meaning (MAW) and spirituality (SAW) at work and positive affect (PA).

$\mathrm{H}_{3}$ : There is a significant positive correlation between job happiness (JH) and job satisfaction (JS).

$\mathrm{H}_{4}$ : There is a significant positive correlation between positive affect (PA) and job satisfaction (JS).

$\mathrm{H}_{5}$ : The job happiness $(\mathrm{JH})$ and positive affect (PA) are mediator variables between meaning (MAW) and spirituality (SAW) at work and job satisfaction (JS).

\subsection{Method}

\section{Participants}

We have conducted this survey between September and November 2012 in two custom organizations in Esfahan and Tehran, Iran. At the time of survey, the organizations had about 400 employees. Research method was correlation one and two hundred and ten employees were asked to participate in this study. Employees filled out research instruments (questionnaires) during working hours. After responding and returning the surveys, we received 204 questionnaires, representing a response rate of $97.14 \%$. The respondents' average age was 38.64 years $(\mathrm{SD}=7.62)$, and the mean of their job tenure was 12.77 years $(\mathrm{SD}=7.36)$. Sixty one and three percent of participants were men and sixty and two percent were women (twenty two and five percent not mentioned their gender). In addition, the majority of participants were married (70.1\%). In terms of educational level, $21.5 \%$ had secondary studies, and $53.5 \%$ had university studies ( $25 \%$ not mentioned their educational level). $17.6 \%$ of the 
participants were acting as manager and the remaining $82.4 \%$ were regular employee. The average time for responding research questionnaires was about 20 minutes and all of the measures in current research were used as a single construct.

\section{Measures}

Meaning at Work: We used the 10-item scale developed by Steger et al. (2012) designed to assess employees' experiences of meaning at work. Employees were asked to report on the extent in which they feel and experience meaning at work. This scale was translated and preliminary studied in Iran by Golparvar (2013b). Sample item was: I have a good sense of what makes my job meaningful. Responses were made on a five-point Likert-type scale ranging from $1=$ "absolutely untrue" to $5=$ "absolutely true". Results of exploratory factor analysis on this scale $(\mathrm{KMO}=.95$, eigenvalue $=10.5$, variance explained $=58.36$ percent) items used in this investigation showed that all items pertaining to meaning at work, loaded into one factor having factor loadings ranging from .34 to .85. Cronbach's alpha of this scale in current research was .95 .

Spirituality at work: To assess spirituality at work, we used eighteen items scale developed and validated by Kinjerski and Skrypnek (2006). Respondents were asked to report on the extent in which experience spirit at work. A sample item is: "I share a strong sense of purpose and meaning with my coworkers about our work". Responses were made on a six-point Likert-type scale ranging from $1=$ "completely untrue" to $6=$ "completely true". Results of exploratory factor analysis on this scale $(\mathrm{KMO}=.94$, eigenvalue $=6.92$, variance explained $=69.17$ percent $)$ items used in this investigation showed that all items pertaining to meaning at work, loaded onto one factor having factor loadings ranging from .58 to .88 . The Cronbach's alpha for this measure was .85 .

Job Happiness: To assess job happiness, we used fifteen items scale developed and validated by Golparvar (2013a). Respondents were asked to report on the extent to which experience job happiness (in three domain: psychological, social and spiritual) in a work day. A sample item is: "how much in a work day you are happy because of your relationship with your coworkers?" Responses were made on a seven-point Likert-type scale ranging from $1=$ "never" to $7=$ "always". Results of exploratory factor analysis on this scale $(\mathrm{KMO}=.95$, eigenvalue $=9.14$, variance explained $=60.92$ percent $)$ items used in this investigation showed that all items pertaining to job happiness, loaded onto one factor having factor loadings ranging from .37 to .79. The Cronbach's alpha for this measure was .9 .

Positive Affect: To assess positive affect, we used fifteen items scale developed and validated by Van Katwyk et al. (2000). Employees were asked to report the degree of their experience during fifteen different positive effects over the past thirty days. A sample item is: "my job over the past 30 days made me feel calm". Responses were made on a five-point Likert-type scale ranging from $1=$ "never" to $5=$ "always". Results of exploratory factor analysis on this scale $(\mathrm{KMO}=.94$, eigenvalue $=8.97$, variance explained $=59.77$ percent) items used in this investigation showed that all items pertaining to positive affect, loaded onto one factor having factor loadings ranging from .52 to .87 . The Cronbach's alpha for this scale was .94.

Job Satisfaction: We assess job satisfaction, using ten items scale developed and validated by Macdonald and Maclntyre (1997). This scale assesses general aspects of job satisfaction such as pay, relations with colleagues and supervisors, and job security (Macdonald \& Maclntyre, 1997). A sample item is: "my wages are good". Responses were made on a five-point Likert-type scale ranging from $1=$ "strongly disagree" to 5 = "strongly agree". Results of exploratory factor analysis on this scale $(\mathrm{KMO}=.9$, eigenvalue $=5.11$, variance explained $=51.1$ percent $)$ items used in this investigation showed that all items pertaining to job satisfaction, loaded onto one factor having factor loadings ranging from .58 to .8 . The Cronbach's alpha for this measure was .89 . 


\section{Results}

Data were analyzed with SPSS-18 to compute correlations and descriptive statistics. It should be said that, in structural equation modeling, each of research variables used as a single indicator. To estimate the research model, we used structural equation modeling (SEM), employing AMOS-16. The means, standard deviations, reliabilities $(\alpha)$ and correlations among the research variables are presented in Table 1.

\section{Table 1}

Means, standard deviations and correlations of the research variables

\begin{tabular}{clccccccc}
\hline Row & Research Variables & M & SD & 1 & 2 & 3 & 4 & 5 \\
\hline 1 & Job Happiness (JH) & 3.54 & 1.19 & $(.9)$ & & & & \\
2 & Job Satisfaction (JS) & 3.12 & 1.02 & $0.69^{* *}$ & $(.89)$ & & & \\
3 & Positive Affect (PA) & 2.55 & 0.72 & $0.64^{* *}$ & $0.74^{* *}$ & $(.94)$ & & \\
4 & Spirituality at Work (SAW) & 3.75 & 1.14 & $0.6^{* *}$ & $0.64^{* *}$ & $0.66^{* *}$ & $(.85)$ & \\
5 & Meaning at Work (MAW) & 3.37 & 1.19 & $0.61^{* *}$ & $0.67^{* *}$ & $0.69^{* *}$ & $0.59^{* *}$ & $(.95)$ \\
\hline
\end{tabular}

Note: $\mathrm{n}=204$, Alpha reliabilities appear in diagonal, $* * p<.01$

As it can be seen in Table 1, consistent with the first to the forth hypotheses $\left(\mathrm{H}_{1}\right.$ to $\left.\mathrm{H}_{4}\right)$ of the survey, the bivariate correlations indicate that spirituality (SAW) and meaning (MAW) at work are positively associated with job happiness $(\mathrm{JH})(\mathrm{r}=.6$ and $\mathrm{r}=.61, p<.01$ respectively). The results also reveal that spirituality (SAW) and meaning (MAW) at work are positively associated with positive affect (PA) (r $=.66$ and $\mathrm{r}=.69, p<.01$ respectively) and job satisfaction (JS) $(\mathrm{r}=.64$ and $\mathrm{r}=.67, p<.01$ respectively). Results presented in Table 1, also show that there was a positive relationship between job happiness $(\mathrm{JH})$ and positive affect (PA) with job satisfaction (JS) $(\mathrm{r}=.69, \mathrm{r}=.74, p<.01$ respectively). The result of structural equation modeling (SEM) for current research conceptual models (Fig. 1) shows that it is necessary to modify the model a bit. Modification indices are the good criteria for revision of structural models for improvement of the goodness of fit indices (Tabachnick \& Fidell, 2007). To improve goodness of fit indices, a path added from spirituality at work (SAW) to job satisfaction (JS). The results of structural equation modeling (SEM) for final and revised models are shown in Table 2 .

\section{Table 2}

The results of structure equation modeling for final and revised research model (Fig. 1)

\begin{tabular}{|c|c|c|c|c|c|}
\hline Row & Paths & $\mathrm{B}$ & $\mathrm{SE}$ & $\beta$ & $\mathrm{R}^{2}$ \\
\hline \multicolumn{6}{|c|}{ Job happiness as a mediator } \\
\hline 1 & Meaning at work (MAW) $\longrightarrow$ Job happiness (JH) & $.17^{*}$ & .08 & $0.18^{*}$ & \multirow{2}{*}{0.528} \\
\hline 2 & Spirituality at Work (SAW) $\longrightarrow$ Job happiness $(\mathrm{JH})$ & $.6^{* *}$ & .1 & $0.57^{* *}$ & \\
\hline 3 & Spirituality at Work (SAW) $\longrightarrow$ Job Satisfaction (JS) & $.32^{* *}$ & .06 & $.33^{* *}$ & \multirow{2}{*}{0.627} \\
\hline 4 & Job happiness $(\mathrm{JH}) \longrightarrow$ Job Satisfaction $(\mathrm{JS})$ & $.49^{* *}$ & .06 & $.52^{* *}$ & \\
\hline \multicolumn{6}{|c|}{ Positive affect as a mediator } \\
\hline 5 & Meaning at work (MAW) $\longrightarrow$ Positive Affect (PA) & $.17^{* *}$ & .06 & $0.26^{* *}$ & \multirow{2}{*}{0.551} \\
\hline 6 & Spirituality at Work (SAW) $\longrightarrow$ Positive Affect (PA) & $.38^{* *}$ & .07 & $0.51^{* *}$ & \\
\hline 7 & Spirituality at Work (SAW) $\longrightarrow$ Job Satisfaction (JS) & $.65^{* *}$ & .08 & $.59^{* *}$ & \multirow{2}{*}{0.61} \\
\hline 8 & Positive Affect (PA) $\longrightarrow$ Job Satisfaction (JS) & $.34^{* *}$ & .06 & $.34^{* *}$ & \\
\hline
\end{tabular}

Note: $\mathrm{n}=204,{ }^{*} p<.05,{ }^{*} * p<.01$

As it can be seen in Table 2, the results for job happiness as a mediator, indicate significant paths from (1) meaning at work (MAW) to job happiness $(\mathrm{JH})(\beta=.18, p<.05),(2)$ spirituality at work (SAW) to job happiness $(\mathrm{JH})(\beta=.57, p<.01)$. In addition, the results indicate significant paths from (3) spirituality at work (SAW) to Job Satisfaction (JS) $(\beta=.33, p<.01)$, and (4) job happiness (JH) to job satisfaction (JS) $(\beta=.52, p<.05)$. The model explained 62.7 percent of the variance in job satisfaction (JS). The results of the research model (Fig. 2- job happiness as a mediator) showed good 
fit with the data. We used several goodness-of-fit indices in assessing the fit of the research model (Tabachnick \& Fidell, 2007). These fit indices include the Chi-square statistic divided by the degrees of freedom ( $\chi 2 / \mathrm{df})$; Incremental Fit Index (IFI), Comparative Fit Index (CFI), Tucker-Lewis coefficient (TLI), Root Mean Residual (RMR) and Root Mean Square Error Approximation (RMSEA).

As suggested in the literature (Steiger, 2007), the following criteria of goodness-of-fit indices were used to assess the model-fit: the $\chi 2 / \mathrm{df}$ ratio is recommended to be less than 3 ; the values of RFI, NFI, CFI, and TLI are recommended to be greater than .90; RMR and RMSEA are recommended to be up to .05, and acceptable up to .08 (Tabachnick \& Fidell, 2007; Steiger, 2007). For current final research model (job happiness as a mediator), Chi-square and the $\chi 2 / \mathrm{df}$ ratio was $3.55(\mathrm{df}=1)$; and other goodness-of-fit statistics such as CFI $=.99$; IFI $=.99$; TLI $=.97 ; \mathrm{RMR}=.016$; RMSEA $=.1$ ) were obtained. These results, except $\chi 2 / \mathrm{df}$ ratio and RMSEA which have marginal values, in other indices are acceptable (Sharma, Mukherjee, Kumar \& Dillon, 2005; Hooper, Coughlan \& Mullen, 2008).

In addition, the results of Table 2, for positive affect as a mediator, indicate significant paths from (5) meaning at work (MAW) to positive affect (PA) $(\beta=.26, p<.01),(6)$ spirituality at work (SAW) to positive affect (PA) $(\beta=.51, p<.01)$. In addition, the results indicate significant paths from (7) spirituality at work (SAW) to job satisfaction (JS) $(\beta=.59, p<.01)$, and (8) positive affect (PA) to job satisfaction (JS) $(\beta=.34, p<.01)$. The model explained 61 percent of the variance in job satisfaction (JS). The results of the research model (Fig. 2- positive affect as a mediator) showed good fit with the data. For final and revised model (positive affect as a mediator), Chi-square and the $\chi^{2 / \mathrm{df}}$ ratio was $2.14(\mathrm{df}=1)$; and also other goodness-of-fit statistics such as CFI = .99; IFI = .99; TLI = .99; RMR= $.01 ; \mathrm{RMSEA}=.07$ were acceptable.

We have also tested one alternative model, in which job happiness and positive affect included in a total model. The result of this model, yielded weak goodness-of-fit statistics $(\chi 2=34.25, p<.05$; $\chi 2 / \mathrm{df}=11.42 ; \mathrm{RMR}=.05 ; \mathrm{RMSEA}=.23$ ). Thus, the model of current research (Fig. 2 ) was preferred.

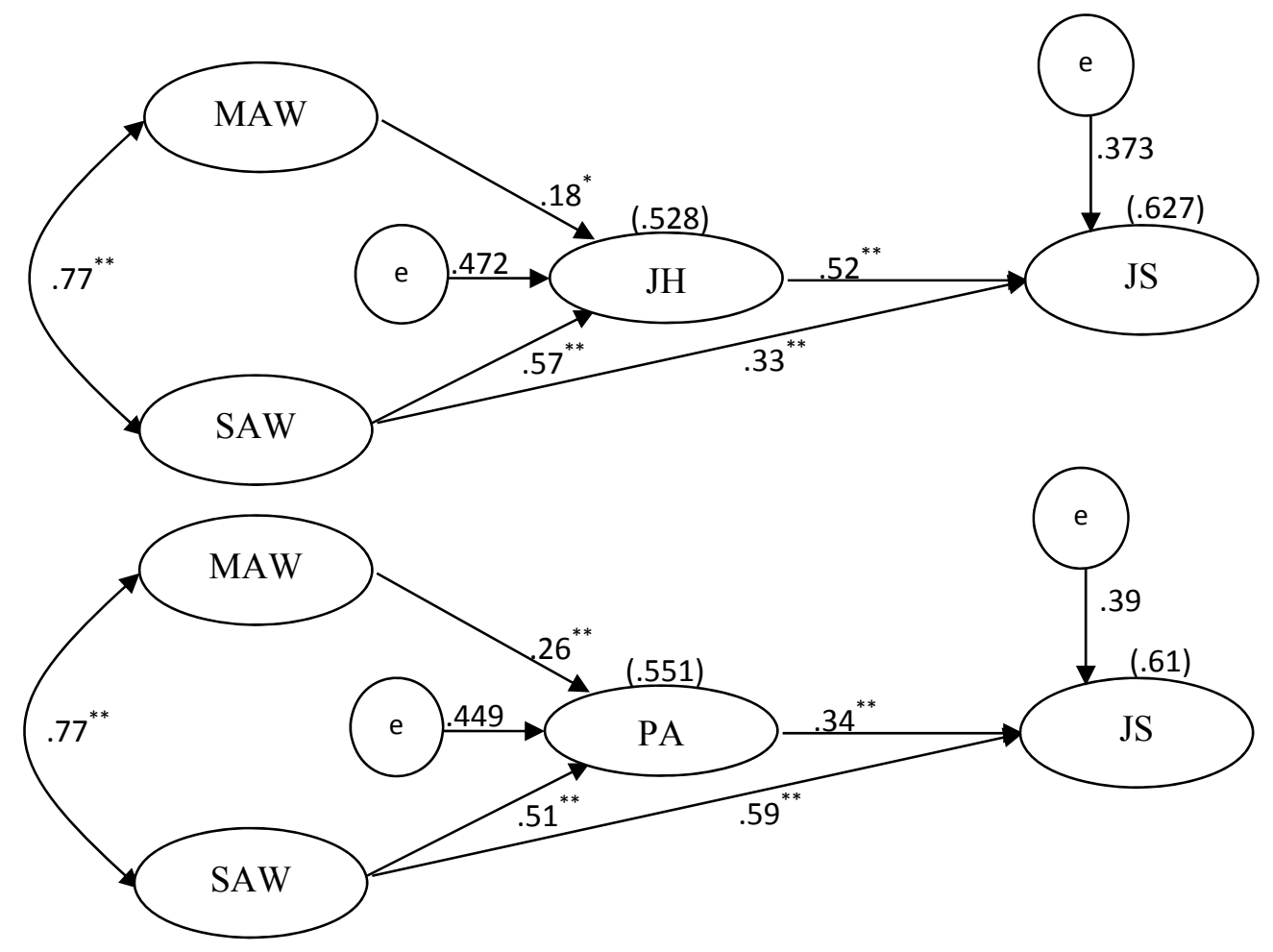

Fig. 2. The final and revised structural models of current research 
In Fig. 2, ovals show latent variables. For preventing confusing Fig. 2, the indicators (items) of the variables are not shown. Statistics are standardized parameters and statistics on parenthesis over the job happiness $(\mathrm{JH})$ and job satisfaction (JS) ovals is the amount of explained variance $\left(\mathrm{R}^{2}\right)$. Indirect effects of meaning at work (MAW) and spirituality at work (SAW) for job satisfaction (JS) through job happiness $(\mathrm{JH})$ and positive affect $(\mathrm{PA})$ are presented in Table 3.

Table 3

Standardized and unstandardized indirect effects in final and revised models of research

\begin{tabular}{clcc}
\hline Row & $\begin{array}{c}\text { Indirect Effects } \\
\text { Job happiness as a mediator }\end{array}$ & $\mathrm{b}$ \\
\hline 1 & Indirect effect of meaning at work (MAW) on job satisfaction (JS) trough job happiness (JH) & $.08^{* *}$ & $.09^{* *}$ \\
2 & Indirect effect of spirituality at work (SAW) on job satisfaction (JS) trough job happiness (JH) & $.29^{* *}$ & $.3^{* *}$ \\
& Positive affect as a mediator & $.11^{* *}$ & $.13^{* *}$ \\
\hline 3 & Indirect effect of meaning at work (MAW) on job satisfaction (JS) trough positive affect (PA) & $.25^{* *}$ & $.25^{* *}$ \\
\hline 4 & Indirect effect of spirituality at work (SAW) on job satisfaction (JS) trough positive affect (PA) & &
\end{tabular}

As it can be seen in Table 3, indirect effects of meaning at work (MAW) on job satisfaction (JS) trough job happiness $(\mathrm{JH})(\mathrm{b}=.08, \beta=.09, p<.05)$, and indirect effects of spirituality at work (SAW) on job satisfaction (JS) trough job happiness $(\mathrm{JH})(\mathrm{b}=.29, \beta=.3, p<.01)$ are significant. Also indirect effects of meaning at work (MAW) on job satisfaction (JS) trough positive affect (PA) $(b=.11, \beta=$ $.13, p<.01$ ), and indirect effects of spirituality at work (SAW) on job satisfaction (JS) trough positive affect (PA) $(\mathrm{b}=.25, \beta=.25, p<.01)$ are significant. To further evaluate, our mediation models, we followed Preacher \& Hayes (2004) procedures to conduct bootstrap analyses in order to provide a more robust test of whether the mediated effects found in the models were statistically significant. The analysis tested the indirect effect of (1) meaning at work (MAW) on job satisfaction (JS) trough job happiness $(\mathrm{JH})$ and positive affect (PA), and (2) spirituality at work (SAW) on job satisfaction (JS) trough job happiness $(\mathrm{JH})$ and positive affect (PA). The results of bootstrap are presented in Table 4.

\section{Table 4}

Bootstrap results of indirect effects in final and revised models of research

\begin{tabular}{|c|c|c|c|c|c|c|c|}
\hline \multirow{2}{*}{ Row } & \multirow{2}{*}{ Paths } & \multirow{2}{*}{$\beta$} & \multirow{2}{*}{ Boot } & \multirow{2}{*}{ SE } & \multicolumn{2}{|c|}{$95 \% \mathrm{CI}$} & \multirow[b]{2}{*}{$p$} \\
\hline & & & & & Low & High & \\
\hline \multicolumn{8}{|c|}{ Job happiness as a mediator } \\
\hline 1 & $\mathrm{MAW} \longrightarrow \mathrm{JH} \longrightarrow \mathrm{JS}$ & .09 & .08 & .002 & .01 & 0.21 & .01 \\
\hline 2 & $\mathrm{SAW} \longrightarrow \mathrm{JH} \longrightarrow \mathrm{JS}$ & .3 & 0.19 & .001 & .08 & .35 & .001 \\
\hline \multicolumn{8}{|c|}{ Positive affect as a mediator } \\
\hline 3 & $\mathrm{MAW} \longrightarrow \mathrm{PA} \longrightarrow \mathrm{JS}$ & .13 & .11 & .001 & .02 & .23 & .001 \\
\hline 4 & $\mathrm{SAW} \longrightarrow \mathrm{PA} \longrightarrow \mathrm{JS}$ & .25 & .25 & .001 & .13 & .44 & .001 \\
\hline
\end{tabular}

As it can be seen in Table 4, the results of 1,000 usable bootstrap resample, reveal that none of the 1,000 usable bootstrap samples had a value less than zero. These results indicate that the mediated effects observed earlier were significant (Preacher \& Hayes, 2004). On the basis of presented results in Table 3 and Table 4, the fifth hypothesis $\left(\mathrm{H}_{5}\right.$, the job happiness $(\mathrm{JH})$ and positive affect (PA) are the mediator variables between meaning (MAW) and spirituality (SAW) at work and job satisfaction (JS)) was supported completely.

\section{Discussion}

In this study, the relationship between meaning and spirituality at workplace were examined with happiness, job-related positive effects and job satisfaction. The findings showed that there was a positive relationship between meaning and spirituality at work with job happiness, job-related positive affect and job satisfaction. These findings are consistent with previous researchers' emphases 
and comments on the role of meaning and spirituality in experiencing of positive affect generally (such as happiness and positive affect) (Lyubomisky \& Lepper, 1999; Downey, 2008; Warr, 2009, 2013; Karakas, 2010; Hasnain et al, 2011; Steger et al, 2012) and specifically (such as job satisfaction) (Albano, 2009; Ho, 2011; Wang \& Yi, 2011; De Kok, 2013; Warr, 2013; Steger et al., 2012). This section of findings shows that meaning and spirituality at work could be considered as phenomena with general affective function (happiness and job-related positive affect) and specific affective function (job satisfaction). From the theoretical viewpoint, meaning and spirituality at work could increase happiness and positive affect and job satisfaction in different ways.

Sense making and tendency to spirituality at an individual level are the basic need for human beings (Karakas, 2010; Hasnain et al., 2011). Such a need like any other need has motivational force. This means that people are forced to try to satisfy it. This effort will be in the sense of having purpose in relation to self, others, and anthropocentric force. In addition, the need for meaning and spirituality like any other needs in the time to be satisfied, create positive affects and emotions (De Kok, 2013). Therefore, it is logical that when people feel that they understand human and spiritual values of their work and job and yet their job and work is a worthwhile, meaningful and significant job, they also experience happiness, positive affect, and job satisfaction. But this is only overall part of the central theme of current study.

The main issue in this study is concerned to more comprehensive theoretical approach that we introduce spirituality based affective spillover approach. This approach is presented in this study based on the study background, has this default that general positive affectivity like happiness and job-related positive affect play mediating role in the relationship between meaning and spirituality at work and job satisfaction that in addition to the cognitive charge it has job focused affective charge (a particular kind of job-specific positive affect) (Duggleby et al, 2009; Wicker, 2011; Warr \& Inceoglu, 2012; Faulk et al, 2012). This part of the prediction of spirituality based affective spillover approach is supported based on two models that have been examined in this relationship in this research. In fact, the results of this study showed that meaning and spirituality before their relationship with job satisfaction have positive relationship with happiness and job-related positive affect. Models similar to the tested models in this study were not available in other research in order to accommodate and compare them. However, this section of the proposed relationships in the final model of the research showed that meaning and spirituality have acceptable capacity to increase levels of happiness and job-related positive affect.

In the next section of the final models, it has obtained positive relationship between happiness and job-related positive affect with job satisfaction. In addition, spirituality at work has a direct relationship with job satisfaction. This part of the evidence primarily shows that spirituality at work compared with meaning at work have broad and more inclusive relationships with affective-focused professional attitudes (specific and micro), such as job satisfaction. The reason probably is that spirituality compared with meaning at work provides a broader normative framework for individual in the context of various experiences of life, such as job experiences of the individual. However, in many current theoretical formulations meaning at work is presented as a part of spirituality at work (Giacalone \& Jurkiewicz, 2010). Therefore, based on these findings, we can say that spirituality compared with meaning at work has a more inclusive and broader strengthen for the public affects (happiness and job-related positive affect) and affective attitudes of particular axis (job satisfaction).

Spirituality based affective spillover aspect in the two research models is associated with the complete mediating role of happiness and job-related positive affect in relationship between meaning at work and job satisfaction and to their partial role in relationship between spirituality at work and job satisfaction. The main idea of this approach is based on the fact that when spirituality and meaning at work nourish two dimensions of affective capital namely happiness and job-related 
positive affect, positive affect spillover will spilled over from happiness and job-related positive affect to more minor area such as job satisfaction and will increase it.

The spillover follows the rule of transferring impact of overall affective areas to minor affective areas in human mental space. It is possible that in the future, in replaceable models compared with the final models of current research, we could see transferring or spillover from job satisfaction to happiness and job-related positive affect. However, logically, these are the general affects such as happiness and job-related positive affect that have power for effect expansion and they are able to influence not only on job satisfaction but also on more micro affective variables in other areas of work and life. The latent idea in the context of explanations and proposed theories in the presented research is introduction of happiness and positive affect as affective capital.

It seems that phenomena such as positive affect and happiness along with some other possible variables could be discussed and followed up as one of a psycho-human capital dimension in future researches. The reason is because these variables have power of generating, dynamics and support for the behavioral, cognitive, and affective variables at workplace. From such a perspective, we can say that meaning and spirituality at work have a serious role in reinforcing of affective capital of human in the form of happiness and job-related positive affect which is needed to use them in future researches and in practical policy for resolving problems of working world.

\section{Conclusions, Implications and Recommendations}

In summary, the result of this study gave some evidences in support of theoretical spiritual based affective spillover approach. The results of this study have important implications in several aspects. First implication is that the results of this research could provide the ground for expansion of affective consequences of spirituality and meaning at work. The current investigation models also showed that spirituality and meaning at work had a considerable power to influence happiness, positive affect and job satisfaction. Second implication is that based on these findings we can say that spirituality compared with meaning at work had broader influences on attitudes and affects in the workplace. Finally, the third implication is that happiness and job-related positive affect are two dimensions of affective capital for human that could nourish affective-based professional attitude as a feeder source. For this reason, interested researchers can attempt to identify other dimensions for affective capital of human and then examined the role of affective capital in the performance, efficacy, attitudes and perceptions beside spiritual capital, psychological capital, and social capital. These studies will determine that does affective capital is a necessary factor for research and theorizing in the behavioral sciences in the workplace or not?

\section{Limitations}

The models presented in this study are not strictly speaking models based on cause and effect, which is why it is necessary to avoid such causal interpretation. The instruments used in this study has been answered in the form of self-reported, therefore there has been likelihood of variance inflation. However, based on available evidence, we can say that self-reported method is the best way to report various affective states. The reason is that affectivity has completely hidden and personal nature. Finally, the last limitation is that the results of this study are relevant to two-service organization in Iran. 


\section{References}

Adawiyah, W., Shariff, M., Saud, M., \& Mokhtar, M. (2011). Workplace spirituality as a moderator in the relationship between soft TQM and organizational commitment. International Journal of Business \& Social Science, 2(10), 93-100.

Albano, J. F. Jr. (2009). Developing a measure and an understanding of the individual experience of happiness at work. Unpublished Doctoral Dissertation in Psychology, Saybrook Graduate School and Research Center, San Francisco, California.

Agho, A. O., Price, J. L., \& Mueller, C. W. (1992). Discriminant validity of measures of job satisfaction, positive affectivity and negative affectivity. Journal of Occupational and Organizational Psychology 65, 185-19.

Ashkanasy, N. M. (2011). International happiness: A multilevel perspective. Academy of Management Perspectives, 25(1), 23-30.

Barsade, S.G., \& Gibson, D.E. (2007). Why does affect matter in organizations? Academy of Management Perspectives, 21, 36-59.

Boehm, J. K., \& Lyubomirsky, S. (2008). Does happiness promote career success? Journal of Career Assessment, 16(1), 101-116.

Bowling, N. A., Eschleman, K. J., \& Wang, Q. (2010). A meta-analytic examination of the relationship between job satisfaction and subjective well-being. Journal of Occupational and Organizational Psychology, 83, 915-934

Brief, A. P., \& Weiss, H. W. (2002). Organizational behavior: Affect in the workplace. Annual Review of Psychology, 53, 279-307.

Brooke, C., \& Parker, S. (2009). Researching spirituality and meaning in the workplace. The Electronic Journal of Business Research Methods, 7(1), 1-10.

Cohrs, J. C., Abele, A.E., \& Dette, D. E. (2006). Integrating situational and dispositional determinants of job satisfaction: findings from three samples of professionals. The Journal of Psychology, 140(4), 363-395.

Clark, L., Leedy, S., McDonald, L., Muller, B., Lamb, C., Mendez, T., et al. (2007). Spirituality and job satisfaction among hospice interdisciplinary team members. Journal of Palliative Medicine, 10(6), 1321-1328.

De Kok, C. A. (2013). Happiness at work: Are job satisfaction, job self- efficacy and trait emotional intelligence related? Unpublished Master of Art Thesis in Psychology, University of South Africa.

De Nevea, J. E., \& Oswald, A, J. (2012). Estimating the influence of life satisfaction and positive affect on later income using sibling fixed effect. PNAS, 109(49), 19953-19958.

Downey, J. (2008). Hierarchy and happiness: The influence of emotion on administrative job satisfaction. Community College Journal of Research and Practice, 32(8), 597-606.

Duckworth, A. L., Quinn, P. D., \& Seligman, M. E. P. (2009). Positive predictors of teacher effectiveness. The Journal of Positive Psychology, 4(6), 540-547.

Duggleby, W., Cooper, D., \& Penz, K. (2009). Hope, self-efficacy, spiritual well-being and job satisfaction. Journal of Advanced Nursing, 65(11), 2376-2385.

Eby, L.T., Mahar, C.P., \& Butts, M.M. (2010). The intersection of work and family life: the role of affect. Annual Review of Psychology, 61, 599-622.

Faulk, K. E., Gloria, C. T., Cance, J. D., \& Steinhardt, M. A. (2012). Depressive symptoms among US military spouses during deployment: The protective effect of positive emotions. Armed Forces \& Society, 38 (3), 373-390.

Fredrickson, B. L. (2009). Positivity. New York, NY: Crown Publishers.

Giacalone, R. A., \& Jurkiewicz, C.L. (2010). Handbook of workplace spirituality and organizational performance. 2ed edition, New York: M.E. Sharpe, Inc.

Gloria, C. T., Faulk, K. E., \& Steinhardt, M. A. (2013). Positive affectivity predicts successful and unsuccessful adaptation to stress. Motivation and Emotion, 37(1), 185-193. 
Golden, T.D., \& Veiga, J.F. (2008). The impact of superior-subordinate relationships on the commitment, job satisfaction, and performance of virtual workers. Leadership Quarterly, 19, 7788.

Golparvar, M. (2013a). Construct and validation of three dimensional scale of job happiness. Unpublished Manuscript, Islamic Azad University, Esfahan Branch, Esfahan, Iran.

Golparvar, M. (2013b). Translate and validation of meaning at work scale in Iran. Unpublished Manuscript, Islamic Azad University, Esfahan Branch, Esfahan, Iran.

Grandey, A. A., Tam, A. P., \& Brauburger, A. L. (2002). Affective states and traits in the workplace: Diary and survey data from young workers. Motivation and Emotion, 26(1), 35-55.

Harrison, D.A., Newman, D.A., \& Roth, P.L. (2006). How important are job attitudes? Meta-analytic comparisons of integrative behavioral outcomes and time sequences. Academy of Management Journal, 49, 305-325.

Hartel, C. E. J., \& Page, M. (2009). Discrete emotional crossover in the workplace: The role of affect intensity. Journal of Managerial Psychology, 24(3), 237-253.

Hasnain, N., Ansari, S.A., \& Samantray, S. (2011). Spirituality and happiness as correlates of wellbeing in religious women. European Journal of Social Sciences, 20(3), 431-442.

Ho, L.S. (2011). Human spirituality and happiness: A tribute to life the source of inspirations, the source of hope, the source of joy. 1th edition, United State of America, Author House, 168p.

Hooper, D., Coughlan, J., \& Mullen, M. R. (2008). Structural equation modeling: Guidelines for Determining Model Fit. The Electronic Journal of Business Research Methods, 6(1), 53 - 60 .

Judge, T.A., Heller, D., \& Klinger, R. (2008). The dispositional sources of job satisfaction: A comparative test. Journal of Applied Psychology, 57(3), 361-372.

Judge, T. A., \& Ilies, R. (2004). Affect and job satisfaction: A study of their relationship at work and at home. Journal of Applied Psychology, 89 (4), 661-673.

Judge, T.A., \& Klinger, R. (2008). Job satisfaction: Subjective well-being at work. In M. Eid \& R.J. Larsen (Eds.), The science of subjective well-being (pp. 393-413). New York: Guilford Press.

Kaplan, S.A., Warren, C.R., Barsky, A.P., \& Thoresen, C.J. (2009). A note on the relationship between affect(ivity) and differing conceptualizations of job satisfaction: Some unexpected findings. European Journal of Work and Organizational Psychology, 18, 29-54.

Karakas, F. (2010). Spirituality and performance in organizations: a literature review. Journal of Business Ethics, 94(1), 89-106.

Kinjerski, V., \& Skrypnek, B.J. (2006). Measuring the intangible: Development of the Spirit at Work Scale. Paper Presented at the Sixty-fifth Annual Meeting of the Academy of Management, Atlanta, GA, $16 \mathrm{pp}$.

Lyubomisky, S., \& Lepper, S. H. (1999). A measure of subjective happiness: Preliminary reliability and construct validation. Social Indicators Research, 46, 137-155.

Macdonald, S., \& Maclntyre, P. (1997). The Generic Job Satisfaction Scale: scale development and its correlates. Employee Assistance Quarterly, 13 (2), 1-16.

Nelson, D. W., \& Knight, A. E. (2010). The power of positive recollections: Reducing test anxiety and enhancing college student efficacy and performance. Journal of Applied Social Psychology, 40(3), 732-745.

Preacher, K. J., \& Hayes, A. F. (2004). SPSS and SAS procedures for estimating indirect effects in simple mediation models. Behavior Research Methods, Instruments, \& Computers, 36 (4), 717 731.

Pryce-Jones, J. (2010). Happiness at work: Maximizing your psychological capital for success. 1st edition, Wiley-Blackwell, West Sussex.

Rode, J. C. (2004). Job satisfaction and life satisfaction revisited: A longitudinal test of an integrated model. Human Relations, 57(9), 1205-1230.

Rosso, B. D., Dekas, K. H., \& Wrzesniewski, A. (2010). On the meaning of work: A theoretical integration and review. Research in Organizational Behavior, 30, 91-127. 
Sharma, S., Mukherjee, S., Kumar, A., \& Dillon, W.R. (2005). A simulation study to investigate the use of cutoff values for assessing model fit in covariance structure models. Journal of Business Research, 58 (1), 935-43.

Steger, M. F., \& Dik, B. J. (2009). If one is searching for meaning in life, does meaning in work help? Applied Psychology: Health and Well-Being, 1, 303-320.

Steger, M.F., Dik, B.J., \& Duffy, R.D. (2012). Measuring meaningful work: The Work as Meaning Inventory (WAMI). Journal of Career Assessment, 20, 322-337.

Steiger, J.H. (2007). Understanding the limitations of global fit assessment in structural equation modeling. Personality and Individual Differences, 42 (5), 893-98.

Tabachnick, B.G., \& Fidell, L.S. (2007). Using multivariate statistics. 5th ed, Boston, MA: Allyn and Bacon.

Van Katwyk, P.T., Fox ,S., Spector, P.E., \& Kelloway, E.K. (2000). Using the job-Related Affective Well-Being Scale (JAWS) to investigate affective responses to work stressors. Journal of Occupational Health Psychology, 5(2), 219-230.

Volmer, J., Niessen, C., Spurk, D., Linz, A., \& Abele, A. E. (2011). Reciprocal relationships between leader-member exchange (LMX) and job satisfaction: A cross-lagged analysis. Applied Psychology, 60(4), 522-545.

Wang, S., \& Yi, X. (2011). It s happiness that counts: Full mediating effect of job satisfaction on the linkage from LMX to turnover intention in Chinese companies. International Journal of Leadership Studies, 6(3), 337-356.

Warr, P. (2009). Environmental "vitamins", personal judgments, work values, and happiness. in S. Cartwright and C. Cooper (eds.) The oxford handbook of organizational well-being (pp. 57-85). Oxford: Oxford University Press.

Warr, P. B. (2013). Jobs and job-holders: Two sources of happiness and unhappiness. In S. A. D, I.Boniwell, \& A. C. Ayers (eds.), The oxford handbook of happiness (pp.733-750). Oxford: Oxford University Press.

Warr, P., \& Clapperton, G. (2009). The joy of work? Jobs, happiness, and you. London: Routledge.

Warr, P. B., \& Inceoglu, I. (2012). Job engagement, job satisfaction, and contrasting associations with person-job fit. Journal of Occupational Health Psychology, 17, 129-138.

Wicker, D. (2011). Job satisfaction: fact or fiction. Bloomington, IN: Author House.

Young, K.W. (2012). Positive effects of spirituality on quality of life for people with severe mental illness. International Journal of Psychosocial Rehabilitation, 16(2), 62-77. 